\title{
Study-related Use of Instructional Videos by Undergraduate Engineering Students
}

\author{
Hennig, Markus and Mertsching, Bärbel \\ GET Lab, University of Paderborn, Germany
}

\begin{abstract}
In this paper, a questionnaire-based survey on the use of online videos by undergraduate engineering students for study-related purposes is presented. Over the last few years, a large number of instructional videos has been uploaded to websites such as YouTube. Due to the widespread distribution of high-speed internet connections and (mobile) devices, such as smartphones or laptops, which are nowadays routinely used by students, online videos are also frequently used in higher education. While much research on this subject focuses on Massive Open Online Courses (MOOCs) or flipped classroom approaches, this survey examines use of videos for self-study, complementary to traditional face-to-face courses. Furthermore, we analyze the acceptance of a characteristic video production style, which uses specific 3D animations to clarify complex connections between technical and mathematical aspects. The results indicate extensive use of short videos which address subjects that are particularly difficult for the students. This survey can help educators to develop an impression of current video use by undergraduate engineering students.
\end{abstract}

Keywords: Study-related Videos; YouTube Videos; Electrical Engineering, 3D Animations, Engineering Mathematics. 


\section{Introduction}

In recent years, private individuals, companies and educational institutions have uploaded a large number of instructional videos covering nearly every imaginable subject to videosharing websites such as YouTube. In many countries, virtually every student owns a smartphone, tablet pc or other (mobile) devices with high-speed internet access nowadays. For example, a baseline study on media usage in 2017 found that $99 \%$ of the 18 to 19 year olds in Germany own a smartphone, of which the major part frequently watches videos from YouTube, which is by far the most popular website in that group of young adults (Feierabend, Plankenhorn, \& Rathgeb, 2017). Therefore, it is not surprising that (incoming) students in higher education frequently use online videos for self-study.

Much research on video usage in higher education focuses on MOOCs and flipped classroom approaches, which have emerged as popular alternative teaching formats (e.g. Muñoz-Merino et al., 2016). MOOCs usually consist of incremental video lectures series and additional material, but have a dropout rate of up to $90 \%$ (Hew \& Cheung, 2014). Besides other reasons, several studies show that students are oftentimes interested in specific subjects only to pinpoint urgent questions just in time when they occur during their learning process (cf. Henderson, Selwyn, \& Aston, 2015; Hew \& Cheung, 2014). This kind of video use becomes particularly relevant when students are preparing themselves for exams (Kay, 2012). The flipped classroom approaches are a format in which students typically prepare themselves for face-to-face courses by working with videos at home. Instead of just following the lecturer in subsequent face-to-face courses, these courses are attended for learning activities such as discussing difficult concepts and problem solving (e.g. Kerr, 2015). While systematic video use is practically essential in MOOCs and flipped classroom approaches, the study presented in this work examines usage behavior for the apparently much more common use of videos for self-study, complementary to traditional face-to-face courses. Besides investigating the frequency and purpose of video use by undergraduate engineering students, we examine their study-related attitude towards online videos and the way they work with these videos.

Based on the example of an undergraduate electrical engineering course (Fundamentals of Electrical Engineering), we also analyze the acceptance of a video production style, which integrates specific 3D animations, and the way in which students work with such videos. In this course, students have to describe electromagnetic fields by working with multiple integrals in 3D space and in different coordinate systems. Such subjects are particularly difficult for the students because they require advanced mathematical knowledge and competencies as well as comprehensive spatial reasoning in 3D space. To support the students, we have developed short videos with specific 3D animations to clarify complex connections between technical and mathematical aspects (Hennig, Mertsching, \& Hilkenmeier, 2015; Hennig \& Mertsching, 2017). 


\section{Preliminary Considerations}

What are the students' general attitudes towards online videos, why do they use them and for which purposes? For the case of lecture recordings, O'Callaghan et al. (2017) answer these (and further related) questions by a comprehensive literature review: In summary, students find lecture recordings useful, see them positive, and even report an influence on their course satisfaction depending on whether such recordings are available are not. Furthermore, students use lecture recordings because it enhances their learning process and especially to fill specific knowledge gaps. As summarized by the authors, students also value the possibility to learn with their individual pace and to be able to review or skip parts of videos depending on their individual needs. The importance of these individual factors is also found by subject-related studies, for example in mathematics (Shé et al., 2017). The findings are therefore in line with the studies related to MOOCs as cited in the introduction, underlining that students particularly use online videos for individually reviewing specific subjects.

Nonetheless, lecture recordings are only one type of instructional videos. Other video production styles are also very common, for example, recordings of freehand-drawings on a tablet pc or of presentation slides, both with aligned audio commentary (Guo, Kim, \& Rubin, 2014). The first part of the study presented in this work investigates the studyrelated use of instructional videos in general, irrespective of specific production styles or producers. The second part of the study addresses our own video production style, which integrates specific 3D animations.

The study presented in this paper addresses undergraduate engineering students and is therefore subject-related. Corresponding investigations from the literature are usually focusing on well-defined learning settings and case studies. For example, Marques et al. (2012) analyze students' video use for an application in the area of groundwater flow and point out the possibilities to visualize theoretical concepts in practice. This example underlines the high potential of video use in engineering education, where a large range of technical phenomena is not directly observable (e.g. electromagnetic fields) due to their physical nature as well as their spatial and time-dependent (dynamic) dimensions (Karapanos, Pöhnlein, \& Fleuren, 2015). By using 3D animations, these processes can be visualized so that students are supported to build dynamic mental 3D models.

\section{Methodology}

For this survey, a paper-and-pencil questionnaire consisting of 23 questions was given to the students of a Fundamentals of Electrical Engineering course (8 ECTS points) at a medium-sized German university in the middle of the last lecture in winter semester 
2017/18 (without prior tests of the questionnaire). Participation in the survey was voluntary and we received responses from 65 students. Parts of the following analysis are referring to different numbers of participants as missing or inconsistent answers were discarded.

The questionnaire consisted of four sections, where the first section surveyed demographic data. The student group consisted of 58 male and 7 female students. The median age of the students was 20 years $(N=64$, mean $=20.42$ years, $s d=2.57$ years $)$. With a fraction of $70.97 \%$, most students were in their first semester and $22.58 \%$ in their second and third semester $(N=62)$. Mostly bachelor students of electrical engineering and closely related degree programs attended the course and the survey.

In the second section of the questionnaire, we used Likert scale and multiple choice questions to ask the students to evaluate our own video production style, which integrates specific 3D animations, and the way students work with such videos. Analogously, we surveyed study-related video use by the students in the third section of the questionnaire. As this might be more interesting than the 3D animations for many readers, we begin with this aspect in the next section of the paper. The fourth section of the questionnaire addressed different types of video production styles.

\section{General Video Use}

Among other aspects, the questions about study-related video use addressed the frequency of use, usage behavior and the purpose of use. The results are summarized in figure 1.

Frequency of study-related video use (one response possible)

\begin{tabular}{|c|c|c|c|}
\hline a $13,85 \%$ & b $52,31 \%$ & c $21,54 \%$ & d $12,31 \%$ \\
\hline a Nearly daily $\quad$ b Nearly weekly $\quad$ c Nearly monthly $\quad$ d Almost never & $N=65$ \\
Usage behavior (one response possible)
\end{tabular}

\begin{tabular}{|l|l|l}
\hline a $11,11 \%$ & b $28,57 \%$ & c $60,32 \%$ \\
\hline
\end{tabular}

Purpose of use (multiple responses possible)

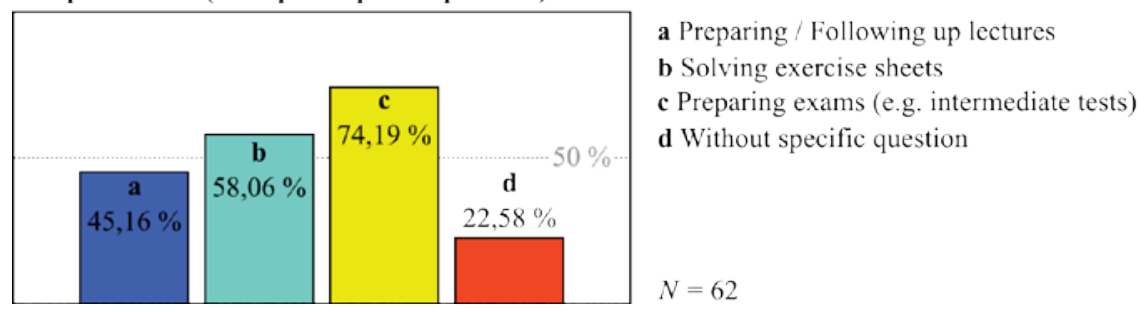

Figure 1: Investigation of study-related video use as reported by the students. 
As can be seen, most students use videos at least on a weekly basis for study-related purposes. This shows that the students frequently integrate instructional videos in their learning process. Note that the questionnaire was given to the students during the lecture period, so that the subsequent examination phase did not start at that time. Students were also asked about their usage behavior when learning with videos. Here, the students could select between typically overflowing videos, watch them completely or watch them completely and additionally work with them by pause, review etc. Here, the third case is predominant. Concerning the purpose of use, most students use videos to prepare exams.

We also asked which devices the students use, when videos are watched during their learning process (multiple responses possible). Here, 90.77\% reported PC or laptop use, $50.77 \%$ reported smartphone use and $32.31 \%$ reported tablet PC use $(N=65)$. Furthermore, $86.89 \%$ of the students reported to exclusively use YouTube and no other websites for watching instructional videos in their learning process $(N=61)$. This is in line with the studies that found YouTube to be the most popular website of young adults (see Introduction). Concerning the subjects, the students predominantly watch videos about mathematics (75,81\%) and physics (64.52\%, $N=61$, multiple answers possible).

\section{Evaluation of 3D Animations}

In winter semester 2017/18, students were provided one of our short videos addressing Gauss's law in electrostatics with specific 3D animations. The video was uploaded to YouTube and has a length of 9 minutes and 5 seconds, see figure 2 for an example frame. Students were informed in the face-to-face courses as well as by mailing lists about the publication of the video. Furthermore, the video was linked from a Wiki which is integrated within the course (cf. Hennig, Mertsching, \& Hilkenmeier, 2015).

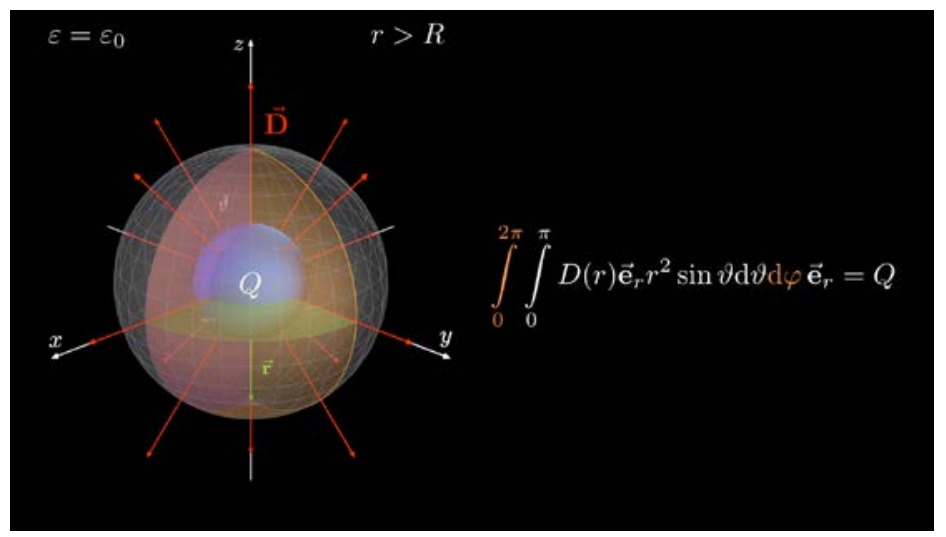

Figure 2: A frame from our video about Gauss's law in electrostatics (Hennig \& Mertsching, 2017). 
Using this video was voluntary and $68.75 \%$ of the students reported that they have seen it ( $N=64)$. Furthermore, we asked the students who have seen this video to report the way they worked with this video (only one response possible). Here, 18.18\% reported to have overflown the video, $47.73 \%$ watched it completely and $34.09 \%$ watched it completely and additionally worked with the video systematically by pause, review etc. Here, students might work more systematically with the video for exam preparation. Based on these results, we conclude that such short videos addressing subjects that are particularly difficult for the students are extensively used.

Additionally, we asked the students to evaluate the video with regard to usefulness, comprehensibility, length, and if they plan to use the video for preparing the final written exam, depending on whether they have already seen the video or not. The results are summarized in table 1. Within the boxplots, the central bars represent the median, while the bottom and top edges indicate the 25th and 75th percentiles. The whiskers correspond to the most extreme data points which are not considered as outliers, while outliers are marked by a '+' symbol. We used the questions with four options to avoid neutral answers and to force the participants to indicate their tendency. As can be seen, the students rate the video positive, where the length is evaluated nearly optimal. Of particular interest is also the finding that most students who have seen the video are also planning to use it for exam preparation. In the fourth section of the questionnaire, we asked the students to select one of four production styles based on single example frames, which they consider most suitable for explaining integral equations, such as Gauss's law in electrostatics. Here, $47.54 \%$ selected our own production style, while only $19.67 \%$ selected lecture recordings. The remaining students selected recordings of freehand-drawings on a tablet pc $(21.21 \%)$ or of presentation slides (11.48\%), both with aligned audio commentary $(N=61)$. 
Table 1: Students' evaluation of the video about Gauss's law in electrostatics, see text for details.

\begin{tabular}{|c|c|c|c|c|c|c|c|c|c|}
\hline Item & Range & $N$ & Median & Mean & SD & Boxplot & & & \\
\hline \multirow{2}{*}{ Usefulness } & \multirow{2}{*}{$\begin{array}{l}\text { very helpful (1) - } \\
\text { not helpful at all (4) }\end{array}$} & \multirow{2}{*}{42} & \multirow{2}{*}{2} & \multirow{2}{*}{1.76} & \multirow{2}{*}{0.69} & 1 & -1 & + & \\
\hline & & & & & & 2 & 3 & 4 & \\
\hline \multirow[t]{2}{*}{ Comprehensibility } & \multirow{2}{*}{$\begin{array}{l}\text { very comprehensive (1) - } \\
\text { not compr. at all (4) }\end{array}$} & \multirow[t]{2}{*}{42} & \multirow[t]{2}{*}{2} & \multirow{2}{*}{1.74} & \multirow[t]{2}{*}{0.70} & 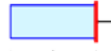 & -1 & + & \\
\hline & & & & & & 2 & 3 & 4 & \\
\hline \multirow[t]{2}{*}{ Length } & \multirow{2}{*}{$\begin{array}{l}\text { too long (1) - } \\
\text { too short (5) }\end{array}$} & \multirow[t]{2}{*}{43} & \multirow[t]{2}{*}{3} & \multirow[t]{2}{*}{2.95} & \multirow[t]{2}{*}{0.65} & + & | & + & + \\
\hline & & & & & & 1 & 3 & 4 & 5 \\
\hline \multirow{2}{*}{$\begin{array}{l}\text { Exam preperation } \\
\text { (video seen) }\end{array}$} & \multirow{2}{*}{$\begin{array}{l}\text { very likely (1) - } \\
\text { very unlikely (4) }\end{array}$} & \multirow{2}{*}{44} & \multirow{2}{*}{1} & \multirow{2}{*}{1.68} & \multirow{2}{*}{0.86} & J & -1 & + & \\
\hline & & & & & & 1 & 3 & 4 & \\
\hline \multirow{2}{*}{$\begin{array}{l}\text { Exam preperation } \\
\text { (video not seen) }\end{array}$} & \multirow{2}{*}{$\begin{array}{l}\text { very likely (1) - } \\
\text { very unlikely (4) }\end{array}$} & \multirow{2}{*}{7} & \multirow{2}{*}{2} & \multirow{2}{*}{2.14} & \multirow{2}{*}{1.35} & & & & \\
\hline & & & & & & 2 & 3 & 4 & \\
\hline
\end{tabular}

Note that these results should be considered as a tendency only, because the students might only be familiar with our own production style in the context of such integral equations. In summary, we conclude that our specific production style is positively received.

\section{Discussion and Future Work}

We contribute a subject-related survey on video use by undergraduate engineering students for self-study. We are not aware of similar investigations from the literature or studies about 3D animations which explicitly clarify complex connections between technical and mathematical aspects. Therefore, this survey can help educators to understand video use by undergraduate engineering students and to develop their own specific videos. Note that we do not claim to proof general rules about optimal video production and refer to (Clark \& Mayer, 2016) for such research. We also do not explicitly discuss or evaluate the effectiveness of video usage, for example with regard to exam results. This is part of our future work. Nonetheless, videos can have significant benefits to student learning outcomes under certain conditions (Clark \& Mayer, 2016; O'Callaghan et al., 2017).

Besides a range of advantages resulting from study-related video use, there are also potential disadvantages. For example, providing videos can have negative effects on attendance and engagement in lectures (O'Callaghan et al., 2017) and restricted communication between students and lecturers can lead to further issues. On the contrary, students frequently and systematically use videos for learning with regard to their individual demands. Therefore, providing videos to complement traditional face-to-face courses is especially attractive for courses with heterogeneous students groups. Such groups 
are particularly found at the beginning of degree programs in higher education as a result of different educational backgrounds of incoming students.

Another possibility to get the students to work even more systematically with (our) videos and to reflect the contents might be to integrate interactive components such as quiz-like questions (e.g. Wachtler et al., 2016).

\section{References}

Clark, R. C., \& Mayer, R. E. (2016). E-learning and the science of instruction: Proven guidelines for consumers and designers of multimedia learning (4th ed.). Hoboken, New Jersey: John Wiley \& Sons.

Feierabend, S., Plankenhorn, T., Rathgeb, T. (2017). JIM-Studie 2017: Jugend, Information, (Multi-)Media [Youth, Information, (Muli-)Media]. Medienpädagogischer Forschungsverbund Südwest. Retrieved from http://www.mpfs.de/studien/jimstudie/2017/

Guo, P. J., Kim, J., \& Rubin, R. (2014). How video production affects student engagement: An empirical study of MOOC videos. Proc. of the first ACM conference on Learning at scale, 41-50.

Henderson, M., Selwyn, N., \& Aston, R. (2017). What works and why? Student perceptions of 'useful' digital technology in university teaching and learning. Studies in Higher Education, 42(8), 1567-1579.

Hennig, M., Mertsching, B., \& Hilkenmeier, F. (2015). Situated mathematics teaching within electrical engineering courses. European Journal of Engineering Education, 40(6), 683-701.

Hennig, M., \& Mertsching, B. (2017). Innovative 3D animations for teaching electromagnetic field theory and its mathematics in undergraduate engineering. Proc. of the 3rd International Conference on Higher Education Advances, 625-632.

Hew, K. F., \& Cheung, W. S. (2014). Students' and instructors' use of massive open online courses (MOOCs): Motivations and challenges. Educational Research Review, 12, 4558.

Karapanos, M., Pöhnlein, M., \& Fleuren, D. (2015). Lernen mit Videos in den Ingenieurund Naturwissenschaften. Ein Erfahrungsbericht aus dem Projekt Open MINT Labs [Learning with videos in engineering and natural sciences. A field report from the project Open MINT Labs]. Retrieved from https://www.e-teaching.org/etresources/pdf/ erfahrungsbericht_2015_karapanos-poehnlein-fleuren_oml.pdf

Kay, R. H. (2012). Exploring the use of video podcasts in education: A comprehensive review of the literature. Computers in Human Behavior, 28(3), 820-831.

Kerr, B. (2015). The flipped classroom in engineering education: A survey of the research. Proc. of the International Conference on Interactive Collaborative Learning, 815-818. IEEE. 
Marques, J. C., Quintela, J., Restivo, M. T., \& Trigo, V. (2012). The use of video clips in engineering education. Proc. of the International Conference on Interactive Collaborative Learning.

Muñoz-Merino, P. J., Ruipérez-Valiente, J. A., Delgado Kloos, C., Auger, M. A., Briz, S., de Castro, V., \& Santalla, S. N. (2017). Flipping the classroom to improve learning with MOOCs technology. Computer Applications in Engineering Education, 25(1), 15-25.

Ní Shé, C., Mac an Bhaird, C., Ní Fhloinn, E., \& O’Shea, A. (2017). Students’ and lecturers' views on mathematics resources. Teaching Mathematics and its Applications, 36(4), 183-199.

O’Callaghan, F. V., Neumann, D. L., Jones, L., \& Creed, P. A. (2017). The use of lecture recordings in higher education: A review of institutional, student, and lecturer issues. Education and Information Technologies, 22(1), 399-415.

Wachtler, J., Hubmann, M., Zöhrer, H., \& Ebner, M. (2016). An analysis of the use and effect of questions in interactive learning-videos. Smart Learning Environments, 3(1). 